\title{
Nutrient-dependent, rapid transition of Vibrio cholerae to coccoid morphology and expression of the toxin co-regulated pilus in this form
}

Correspondence

Ronald K. Taylor

ronald.k.taylor@dartmouth.edu

Received 25 January 2011

Revised 22 June 2011

Accepted 15 July 2011

\author{
Shelly J. Krebs and Ronald K. Taylor
}

\author{
Department of Microbiology and Immunology, Dartmouth Medical School, Hanover, NH 03755, \\ USA
}

\begin{abstract}
The acute diarrhoeal disease cholera is caused by the aquatic pathogen Vibrio cholerae upon ingestion of contaminated food or water by the human host. The mechanisms by which $V$. cholerae is able to persist and survive in the host and aquatic environments have been studied for years; however, little is known about the factors involved in the adaptation or response of $V$. cholerae transitioning between these two environments. The transition from bacillary to coccoid morphology is thought to be one mechanism of survival that $V$. cholerae uses in response to environmental stress. Coccoid morphology has been observed for $V$. cholerae while in a viable but non-culturable (VBNC) state, during times of nutrient limitation, and in the water-diluted stool of cholera-infected patients. In this study we sought conditions to study the coccoid morphology of $V$. cholerae, and found that coccoid-shaped cells can express and produce the virulence factor toxin co-regulated pilus (TCP) and are able to colonize the infant mouse to the same extent as bacillus-shaped cells. This study suggests that TCP may be one factor that $V$. cholerae utilizes for adaptation and survival during the transition between the host and the aquatic environment.
\end{abstract}

\section{INTRODUCTION}

The bacterium Vibrio cholerae is able to exist in two very different environments: the small intestine and aquatic reservoirs. $V$. cholerae must be able to transition between these environments and adapt to its surroundings in order to survive. $V$. cholerae is a Gram-negative, motile bacterium that was first described by Koch as having a bacillary shape (Koch, 1884). It is the aetiological agent of the acute diarrhoeal disease cholera, which is acquired by oral ingestion of contaminated food or water. $V$. cholerae is divided into different serogroups based upon the LPS structure located on the bacterial cell surface. Although over 200 serogroups of $V$. cholerae have been identified, only two are responsible for the major epidemics of the disease: $\mathrm{O} 1$ and O139 (reviewed by Kaper et al., 1995). Epidemic strains of $V$. cholerae require two genetic elements to cause disease, the Vibrio pathogenicity island (VPI), which contains the toxin co-regulated pilus (TCP) gene cluster $(t c p)$, and CTX $\varphi$, which encodes the cholera toxin (Karaolis et al., 1999). Both TCP and cholera toxin are coordinately regulated under the control of a virulence regulatory cascade known as the ToxR regulon, in which ToxT is the direct activator of both $t c p$ and ctx (Bina et al., 2003; Taylor et al., 1986). TCP is essential for colonization of the small intestine, and cholera toxin is

Abbreviations: $\alpha$-, anti-; CVEC, conditionally viable environmental cells; FESEM, field emission scanning electron microscopy; TCP, toxin coregulated pilus; VBNC, viable but non-culturable. responsible for the voluminous diarrhoea associated with the disease. TCP appears as large bundles of filaments composed of polymerized TcpA, which facilitate microcolony formation via pilus-mediated bacterial interactions (Kirn et al., 2000). Microcolony formation by TCP is an essential step in colonization of the small intestine for delivery of the cholera toxin to epithelial cells, and therefore is a prerequisite to establishing a productive infection (Herrington et al., 1988). V. cholerae O1 tcp mutants are unable to form microcolonies, which directly relates to an inability to colonize (Kirn et al., 2000).

In aquatic environments, $V$. cholerae is largely found associated with insects and water plants, and on the chitinaceous surfaces of zooplankton and crustaceans (Halpern et al., 2004; Islam et al., 1989; Tamplin et al., 1990). Culturing V. cholerae from the aquatic environment by conventional methods has been notoriously difficult, although $V$. cholerae cells are detectable in environmental samples by fluorescent antibodies and other methods (Huq et al., 1990; Kamruzzaman et al., 2010). Discoveries in the past 20 years have revealed the existence of a dormant, viable but non-culturable (VBNC) state into which $V$. cholerae enters in response to nutrient deprivation, decreased temperature, and other environmental signals (reviewed by Colwell, 2000; Oliver, 2005; Rice et al., 2000). Alternatively, these environmental survival forms of bacteria have also been recently referred to as 'conditionally viable environmental cells' (CVEC) (Kamruzzaman et al., 
2010). When in this state, the bacteria are not culturable on conventional growth media, although the cells remain viable and display active metabolism (Rahman et al., 1994) and transcription (Lleò et al., 2000), and can divide again upon restoration of favourable environmental conditions (i.e. nutrient supplementation, increased temperature, host environment) (Kamruzzaman et al., 2010; Nilsson et al., 1991; Smith \& Oliver, 2006a). In the laboratory, incubating bacterial cells at decreased temperatures and in nutrientlimiting growth media promotes the VBNC state, after which the bacteria fail to form colonies on solid media (Carroll et al., 2001; Chaiyanan et al., 2001, 2007). In contrast, bacterial cells incubated in nutrient-limiting media, without decreased temperature, are able to grow on laboratory medium for an extended period of time until eventually entering into the VBNC state (Chaiyanan et al., 2007; Felter et al., 1969; Oliver et al., 1991).

The observation that $V$. cholerae cells undergo gross alterations in cell morphology from curved rods (hereafter referred to as rod-shaped) to round, coccoid-shaped cells was first described while cells were in a VBNC state (Carroll et al., 2001; Chaiyanan et al., 2001, 2007; Johnston \& Brown, 2002). This morphological conversion from rod-shaped to coccoid cells is not exclusively found in VBNC cells, but has also been observed during times of nutrient limitation (Baker et al., 1983; Henrici, 1925). Earlier studies concluded that the transition to a coccoid morphology might convey a selective advantage that would allow prolonged survival in the aquatic environment when encountering insufficient nutrient concentrations (Baker et al., 1983). Decreasing size would enable the coccoid cell to have the greatest surface area for nutrient uptake while maintaining the least amount of cell mass (Baker et al., 1983). In addition, these coccoid cells, as observed in Vibrio vulnificus, have an increased resistance to cold shock, heat shock, sonication, ethanol, and mechanical stress (Weichart \& Kjelleberg, 1996), contributing to survival and persistence in the environment. Thus, it has been suggested that the morphological conversion to a coccoid state may be a general survival mechanism of $V$. cholerae.

Morphology conversion into a coccoid cell has been observed in many other pathogenic bacteria as well. In a distinct phase of urinary tract infection, uropathogenic Escherichia coli (UPEC) organizes into a biofilm-like community consisting of coccoid bacterial cells that ultimately fill most of the cytoplasm of urinary tract epithelial cells (Justice et al., 2004). Also, E. coli BJ4 has been shown to exist in a coccoid state in the intestine after differentiation, and there is a natural selection for this coccoid-type cell in the host environment (Krogfelt et al., 1993). Further studies in E. coli have shown that these coccoid cells can divide (Cooper, 1997; Corbin et al., 2002), and that the regulatory factor RodZ, membrane protein RodA and MreB are associated with cell rounding (Corbin et al., 2002; Signoretto et al., 1996). In the case of $V$. cholerae, the cells have been observed primarily in a rodshaped form in the small intestine. However, Faruque et al. (2006) observed V. cholerae in coccoid and rod-shaped morphology in stools of cholera-infected patients diluted in water. Conversion of the bacteria into a coccoid form must happen either in the small intestine near the end of the infection or after dissemination into the environment. Faruque and co-workers have also found a population of $V$. cholerae in aggregates in both the rod and the coccoid form in the stool (Kamruzzaman et al., 2010) that is able to colonize the infant mouse model 10-100-fold better than the reference strain (Faruque et al., 2006). Earlier studies by Bina et al. (2003) using microarrays demonstrated that $t c p$ is expressed in stool samples, albeit at low levels compared with optimal in vitro conditions. Since $V$. cholerae must express tcp to participate in microcolony formation (Kirn \& Taylor, 2005), these observations led us to the hypothesis that coccoid and bacillus-shaped cells express tcp in these aggregates, giving them a distinct advantage in transmission and survival in the aquatic environment.

The aim of this study was to efficiently induce the conversion of the rod-shaped form to the coccoid form of $V$. cholerae to further investigate the characteristics of this morphology, independent of being in a VBNC state. Here we report that $V$. cholerae changes morphology from rods to cocci when incubated in $50 \%$ conditioned medium starting at $3 \mathrm{~h}$. This conversion into a coccoid state increases with incubation time, and by $24 \mathrm{~h}$ more than $90 \%$ of the total viable cells are in coccoid morphology. These coccoid cells are observed both as single cells and in aggregates. We also demonstrate that $V$. cholerae in coccoid morphology is able to express tcp, and that these coccoid cells are not at a disadvantage compared with rod-shaped cells in colonizing the infant mouse small intestine.

\section{METHODS}

Bacterial strains and growth conditions. Strains used in this study are outlined in Table 1. O1 V. cholerae strain O395 was used for all experiments unless noted otherwise. Strains were stored at $-80{ }^{\circ} \mathrm{C}$ in Luria-Bertani (LB) medium (Hulbert \& Taylor, 2002) containing $30 \%(\mathrm{v} / \mathrm{v})$ glycerol. $V$. cholerae strains were grown in LB broth supplemented with streptomycin at $30{ }^{\circ} \mathrm{C}$ for $16 \mathrm{~h}$, with shaking. Cultures were then diluted $1: 1$ with fresh $\mathrm{LB}(1 \mathrm{ml}$ culture: $1 \mathrm{ml}$ fresh LB) in a 12 -well plate and placed back in the $30{ }^{\circ} \mathrm{C}$ incubator (without shaking) for various amounts of time in this $50 \%$ conditioned medium (CM50). The $0 \mathrm{~h}$ time point indicates the time when overnight cultures were diluted $1: 1$ with no additional incubation. Viability was determined by quantifying the number of viable cells with the LIVE/DEAD BacLight Bacterial Viability and Counting kit from Molecular Probes. Total cell counts were determined by quantifying the total numbers of viable and nonviable cells, and culturability was determined by plating cultures on solid LB agar and counting the total number of c.f.u. Streptomycin was used at a concentration of $100 \mu \mathrm{g} \mathrm{ml}^{-1}$ in LB and LB agar when performing the competitive index, and X-Gal was used in LB agar at $40 \mu \mathrm{g} \mathrm{ml}-1$.

Fluorescence microscopy. After staining with the LIVE/DEAD BacLight Bacterial Viability and Counting kit, cells were placed on glass slides without fixation and examined with an Olympus IX-70 confocal fluorescence microscope. Images were captured using FluoView software (Olympus). More than 10 fields of view were 
Table 1. Bacterial strains used in this study

\begin{tabular}{|lll|}
\hline Strain & \multicolumn{1}{c|}{ Characteristic(s) } & Reference or source \\
\hline O395 & O1 classical Ogawa, Sm ${ }^{\mathrm{r} *}$ & Taylor et al. $(1987)$ \\
CVD112 & O139 & Laboratory collection \\
MBN142 & CG842 $\Delta$ toxT/tcpA-lacZ & Nye et al. $(2000)$ \\
MBN135 & CG842 tcpA-lacZ & Nye et al. $(2000)$ \\
SJK166 & O395 promoter of ToxT-GFP & Nancy Beck $\dagger$ \\
SJK174 & O395 $\Delta$ toxR, promoter of ToxT-GFP & Nancy Beck \\
\hline
\end{tabular}

${ }^{*}$ Streptomycin resistant.

$\nmid$ University of Michigan Medical School.

examined per slide for quantitative analysis. Expression of ToxT was assessed by fluorescence of GFP after incubation in CM50 for 0 or $48 \mathrm{~h}$ with or without toxR.

Field emission scanning electron microscopy (FESEM). To view bacterial cells using FESEM, Formvar-coated coverslips were added to 12 -well plates during incubation in CM50 (see growth conditions) and incubated at $30{ }^{\circ} \mathrm{C}$ for various lengths of time. During nutrient supplementation, overnight cultures were diluted $1: 1$, placed in a 12 well plate with a Formvar-coated coverslip, and incubated at $30{ }^{\circ} \mathrm{C}$ for an additional 12, 24 or $48 \mathrm{~h}$. Prior to fixation, either glucose was added to the well and mixed to achieve a final concentration of $1 \%$, or the Formvar-coated coverslip was transferred to a well containing $2 \mathrm{ml}$ fresh medium and placed back in the $30{ }^{\circ} \mathrm{C}$ incubator for an additional hour of incubation. At each time point, the coverslips were removed and fixed with $2.5 \%$ glutaraldehyde, $0.1 \mathrm{M}$ sodium cacodylate in PBS for $1 \mathrm{~h}$. After washing with $0.1 \mathrm{M}$ sodium cacodylate ( $\mathrm{pH} 7.4)$, samples were dehydrated through an ethanol series and then critical point-dried using a Samdri 795 critical point dryer (Tousimis). Dried samples were coated with $3 \mathrm{~nm}$ of osmium, using an SPI plasma coater (SPI Supplies). Images were generated at $15 \mathrm{kV}$ by an FEI XL-30 (FEI) field emission gun scanning electron microscope (FEG-SEM). Images were taken at each time point, and the numbers of coccoid and rod-shaped cells were quantified and means taken from greater than 10 different micrographs.

Immuno-FESEM. To immunolabel the bacterial whole cell or TCP, Formvar-coated coverslips were removed from the bacterial inoculum (see above) at each time point and fixed for $1 \mathrm{~h}$ with $4 \%$ paraformaldehyde, $0.1 \mathrm{M}$ sodium cacodylate in PBS, at room temperature. Samples were washed twice in Tris-buffered saline/Tween (TBST) prior to blocking in $3 \% \mathrm{BSA} / \mathrm{TBST}$ for $1 \mathrm{~h}$. After blocking, samples were incubated with anti-TcpA6 ( $\alpha$-TcpA6) peptide antibody (Sun et al., 1991), pre-immune sera, or $\alpha$-O1 monoclonal antibody (Cholera DFA, New Horizons Diagnostics) at a 1:100 dilution for $2 \mathrm{~h}$ at room temperature. After several wash steps, the samples were incubated with secondary antibody (goat $\alpha$-rabbit to label TCP or goat $\alpha$-mouse to label the bacterial whole cell) conjugated to $18 \mathrm{~nm}$ colloidal gold particles (Jackson ImmunoResearch Laboratories) at a 1:50 dilution for $30 \mathrm{~min}$. Samples were washed again several times before a final fixation with $2.5 \%$ glutaraldehyde, $0.1 \mathrm{M}$ sodium cacodylate for $3 \mathrm{~h}$. Samples were then dehydrated, critical point-dried and examined as described above.

$\boldsymbol{\beta}$-Galactosidase activity. $\beta$-Galactosidase activity was determined according to the method of Miller (1972) with the following modifications. Cultures were grown at $37{ }^{\circ} \mathrm{C}$ with a starting $\mathrm{pH}$ of 6.5 (TCP minimally inducing conditions) for $16 \mathrm{~h}$ before incubation in CM50 under TCP-inducing conditions $\left(30^{\circ} \mathrm{C}\right.$, starting $\mathrm{pH}$ of 6.5$)$ or non-inducing conditions $\left(37^{\circ} \mathrm{C}\right.$, starting $\mathrm{pH}$ of 8.5$)$. Due to the morphology change of the bacterial cells, specific activity was calculated using the protein concentration determined by the bicinchoninic acid (BCA) procedure (Pierce) rather than the optical density of the culture at $600 \mathrm{~nm}$.

Protein electrophoresis and Western blot analysis. Cells were harvested by centrifugation, resuspended in PBS and diluted in $2 \times$ SDS-PAGE loading buffer. Samples containing equal amounts of total protein were separated on an SDS- $12.5 \%$ polyacrylamide gel. Protein estimation was carried out using the BCA Protein Assay kit (Pierce) with BSA as a standard. For immunodetection, proteins were electroblotted onto a nitrocellulose membrane at $4{ }^{\circ} \mathrm{C}$ in transfer buffer ( $25 \mathrm{mM}$ Tris, $192 \mathrm{mM}$ glycine, $20 \%$ methanol, $\mathrm{pH} 8.3$ ) with a wet transfer apparatus (Bio-Rad Laboratories) (Taylor et al., 1987). The membrane was blocked with $3 \%$ BSA in $1 \times$ TBST for $2 \mathrm{~h}$. Antisera containing polyclonal antibodies raised against the synthetic peptide TcpA6 were then applied at 1:10 000 dilution in blocking buffer (Sun et al., 1991). Horseradish peroxidase-conjugated goat $\alpha$-rabbit IgG secondary antibody was added at a 1:10 000 dilution in TBST. Reactive protein bands were detected using an ECL kit (Amersham).

In vivo competitive index analysis. For the in vivo competitive index determinations, $\mathrm{O} 395$ was grown at $30{ }^{\circ} \mathrm{C}$ for $16 \mathrm{~h}$, diluted $1: 1$ with fresh medium, and incubated at $30{ }^{\circ} \mathrm{C}$ for another $3,8,12,24$ or $48 \mathrm{~h}$. At each of these time points, samples were mixed with an equal cell number of the reference strain, CG842 (O395 $\Delta$ lacZ), which began growth $16 \mathrm{~h}$ prior to each time point (see Fig. 7a for further clarification). Three- to five-day-old CD1 mice from mixed litters were orally inoculated with $50 \mu \mathrm{l}$ of the mixture and incubated at $30{ }^{\circ} \mathrm{C}$ for $24 \mathrm{~h}$. The bacteria were then recovered by homogenizing harvested intestines in $3 \mathrm{ml} \mathrm{10 \% (v/v)} \mathrm{glycerol} \mathrm{with} \mathrm{a} \mathrm{Tissue} \mathrm{Tearor} \mathrm{homogenizer}$ (Fisher Scientific). The homogenate was appropriately diluted and plated on solid medium containing streptomycin and X-Gal. The competitive index was calculated by dividing the output ratio of the test strain to reference strain recovered from the intestine, by the input ratio of the test strain to reference strain in the original inoculum. The competitive index was the mean of at least five mice for each strain tested.

\section{RESULTS}

\section{V. cholerae transitions to coccoid morphology during incubation in $\mathrm{CM} 50$}

In earlier studies, conversion from rod to coccoid morphology by $V$. cholerae was detected either in nutrient-free media after approximately 15 days of incubation or by incubating cells for five or more days at $4{ }^{\circ} \mathrm{C}$ in artificial seawater (Baker et al., 1983; Carroll et al., 2001; Chaiyanan et al., 2001, 2007). Incubation at $4{ }^{\circ} \mathrm{C}$ results in the cells entering a VBNC state. 
To study the conversion of $V$. cholerae from rod to coccoid form in the least amount of time and without its being in a VBNC state, primed nutrient-rich bacterial cells were incubated in $50 \%$ conditioned medium (CM50) at $30{ }^{\circ} \mathrm{C}$ for various amounts of time (outlined in Methods). Coccoid cells were visualized beginning at $3 \mathrm{~h}$ using FESEM. To confirm that the coccoid cells were $V$. cholerae, rather than contaminants, monoclonal antibodies specific to $\mathrm{O} 1 \mathrm{~V}$. cholerae LPS were utilized in conjunction with secondary antibodies conjugated to $18 \mathrm{~nm}$ gold particles. Both cell morphologies were positively labelled with these specific $\alpha$ O1 LPS antibodies, confirming that both types of cells, rodshaped and coccoid, were O1 V. cholerae (Fig. 1a). Immunolabelling was also found on the LPS-sheathed flagellum (Fig. 1a). $\alpha$-TcpA antibody, labelling the pilus structure, was used as a positive control (Fig. 1b). Since the $\alpha$-O1 antibodies are specific to O1 V. cholerae LPS and not O139 V. cholerae LPS, immuno-labelling $\mathrm{O} 139$ bacterial cells with $\alpha$-O1 antibodies was used as a negative control (Fig. 1c). As expected, there was no antibody recognition of O139 V. cholerae by $\alpha$-O1 antibodies. As seen in previous studies, $V$. cholerae can transition to a coccoid morphology from as early as $3 \mathrm{~h}$ when incubated in CM50.

\section{Transition from rod to coccoid morphology increases over time, and coccoid cells are viable and culturable}

Since coccoid cells were first observed after $3 \mathrm{~h}$ of incubation, we wanted to determine whether we could detect more cells in coccoid morphology if we allowed the cultures to incubate for longer in CM50. Overnight cultures were diluted $1: 1$ in 12-well plates and incubated at $30{ }^{\circ} \mathrm{C}$ for $3,8,12$ or $24 \mathrm{~h}$. After fixation, FESEM was used to visualize these samples, and the number of rodshaped and coccoid cells was quantified. After $3 \mathrm{~h}$ of incubation, approximately $95 \%$ of the cells were rods and $5 \%$ of the cells were cocci (Fig. 2, 3 h). After $8 \mathrm{~h}$ of incubation, the number of rod-shaped cells decreased to around $55 \%$, and cells in coccoid morphology increased to $45 \%$ (Fig. 2, $8 \mathrm{~h}$ ). By $12 \mathrm{~h}$, the percentage of cocci increased to approximately $70 \%$, and after $24 \mathrm{~h}$, more than $90 \%$ of the cells were in coccoid morphology, with fewer than $10 \%$ of the cells remaining in rod morphology. It is important to note that coccoid cells were observed both as single cells (Fig. 1) and in aggregates (Fig. 2). Additionally, TCP, known to be important in microcolony formation (Kirn et al., 2000), was observed in these aggregates (Fig. 2).

To determine whether coccoid cells under these conditions are viable, the LIVE/DEAD BacLight Bacterial Viability and Counting kit from Molecular Probes was used to view and quantify viable bacterial cells and obtain total counts of bacteria (Boulos et al., 1999). SYTO 9 is a nucleic acid marker that stains all cells green, while propidium iodide only penetrates cells in which the cell membrane has been compromised, staining them red. Therefore, propidium iodide only stains non-viable cells, and viable cells can be distinguished from non-viable cells by fluorescence. Cultures were incubated for $8,12,24,48$ and $171 \mathrm{~h}$ ( 1 week) at $30{ }^{\circ} \mathrm{C}$, as described above, before the cells were stained and visualized using fluorescence microscopy. (a)
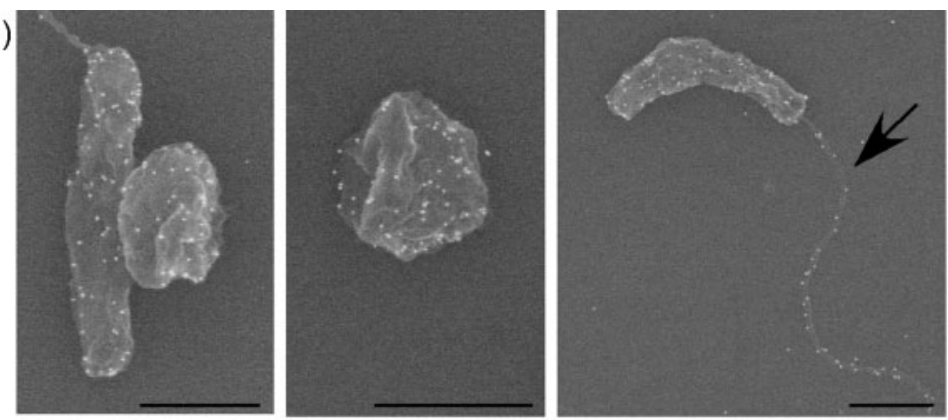

(b)
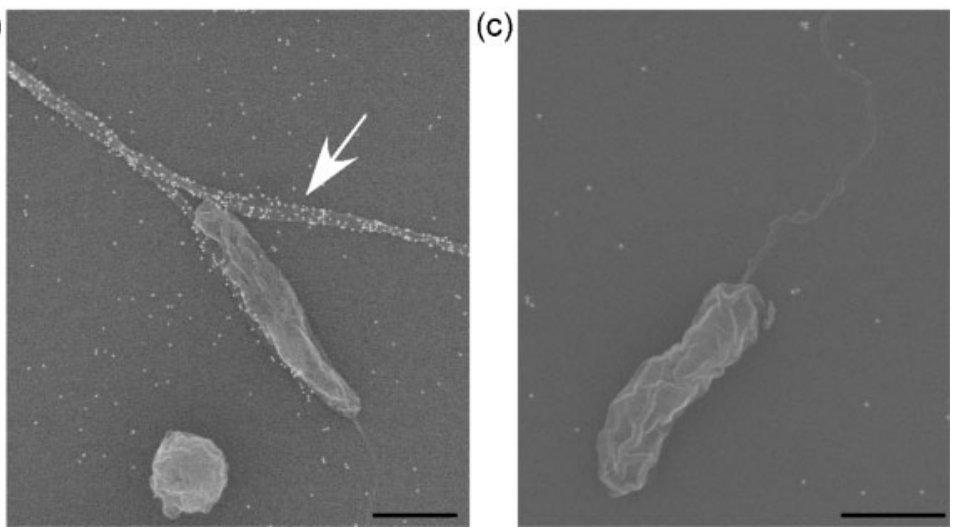

Fig. 1. Electron micrographs of immunolabelled $V$. cholerae cells in rod-shaped and coccoid morphology. (a) O1 classical wildtype $V$. cholerae rod- and coccoid-shaped cells immunolabelled with $\alpha-\mathrm{O} 1$ monoclonal antibodies. The black arrow indicates an LPSsheathed flagellum. (b) $\mathrm{O} 1$ classical wild-type $V$. cholerae immunolabelled with $\alpha$-TcpA antibodies, indicated by a white arrow (positive control). (c) 0139 wild-type V. cholerae incubated with $\alpha-\mathrm{O} 1$ antibodies (negative control). Bars, $1 \mu \mathrm{m}$. 
$3 \mathrm{~h}$

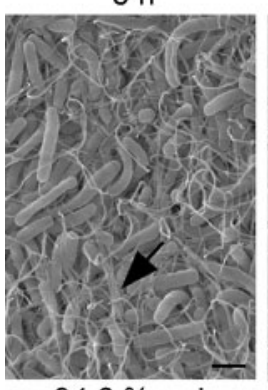

$94.6 \%$ rods

$5.4 \%$ cocci
$8 \mathrm{~h}$

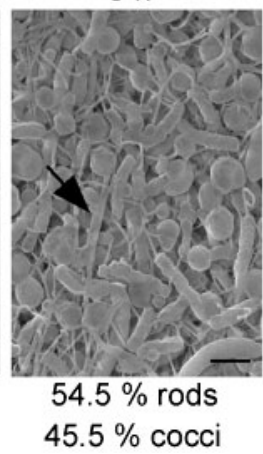

$12 \mathrm{~h}$

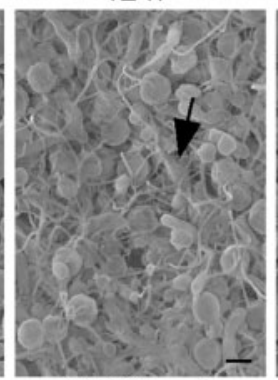

$30.3 \%$ rods

$69.7 \%$ cocci

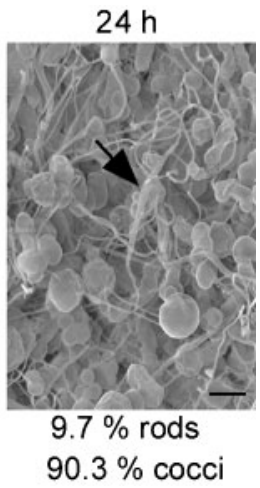

Fig. 2. Electron micrographs of $\mathrm{O} 1$ classical wild-type $V$. cholerae cells transitioning from rod to coccoid morphology after incubation in CM50 for 3, 8, 12 and $24 \mathrm{~h}$. The number of bacteria in coccoid and rod morphology was quantified from multiple micrographs, and the percentages of these cells in each morphology are given below each representative micrograph. Arrows indicate TCP. Bars, $1 \mu \mathrm{m}$.
Similar to Fig. 2, bacterial cells in coccoid morphology were observed, and the transition from rods to cocci increased over time (Fig. 3). As determined by BacLight, these coccoid cells were viable (Fig. 3a), as represented by the green fluorescence of the nucleic acid marker SYTO 9 and absence of propidium iodide red fluorescence. Viable bacterial cells were quantified, and a graphical representation of the percentage of viable cells of each morphology is shown over time in Fig. 3(b). Similar to what was observed in Fig. 2, after $8 \mathrm{~h}$ the numbers of viable cells in coccoid and rod morphology were approximately equal (Fig. 3b). At $24 \mathrm{~h}$, approximately $90 \%$ of the viable cells were in coccoid morphology. After $48 \mathrm{~h}$, more than $95 \%$ of the total viable cells were in coccoid morphology, and this ratio was maintained for 1 week of incubation prior to the termination of the experiment. Total cell counts were maintained at between $1 \times 10^{7}$ and $1 \times 10^{8}$ throughout incubation, and the overall viability of these cells was maintained at a mean of $85 \%$ (Fig. 4). Cultures at each time point were plated on solid growth medium to determine whether these coccoid cells were culturable, or whether they were in a VBNC state. Culturability did decrease slightly with time (Fig. 4); however, up to $1 \times 10^{6}$ cells were still culturable after 1 week of incubation (Fig. 4). These coccoid cells were notably different from cells in a VBNC state, since VBNC cells are virtually undetectable on solid growth medium (Carroll et al., 2001; Smith \& Oliver, 2006a). Altogether, these data suggest that $V$. cholerae cells in coccoid morphology are viable, and not purely in a VBNC state under these conditions. We continued to use these conditions for the remainder of the experiments to study the characteristics of $V$. cholerae in coccoid morphology without being in a VBNC state.

\section{Nutrient supplementation causes reversion from coccoid to rod morphology}

It has been documented that during nutrient deprivation, $V$. cholerae undergoes gross alterations in cell morphology from rods to cocci with increasing time of exposure (Baker et al., 1983). To determine whether nutrient deprivation had an effect on the transition from rod to coccoid morphology under our conditions, nutrients were added to cultures after 12, 24 and $48 \mathrm{~h}$ of incubation in CM50 (after the majority of the cells transitioned to cocci). Nutrients were added in the following two ways: (1) glucose was added to the culture to achieve a final concentration of $1 \%$, and (2) $2 \mathrm{ml}$ fresh LB was added to the culture (see Methods). After the addition of either nutrient, the cultures were allowed to incubate for one additional hour at $30{ }^{\circ} \mathrm{C}$. As shown above in Fig. 2, prior to the addition of nutrients, approximately $70 \%$ of all cells were in coccoid morphology after $12 \mathrm{~h}$ of incubation in CM50. However, after the addition of glucose, coccoid morphology decreased to fewer than $15 \%$, and rod morphology increased to more than $85 \%$ of the cells (Fig. 5a). Likewise, after the addition of fresh LB, coccoid morphology decreased to fewer than $30 \%$, and rod morphology increased to more than $70 \%$ of the cells (Fig. 5b). Similar results were observed with cells incubated at 24 and $48 \mathrm{~h}$ in CM50, such that prior to the addition of nutrients, the majority of cells were in coccoid morphology, and after the addition of nutrients, the majority of cells were in rod morphology. To determine whether the increase of rod morphology after the addition of nutrients was due to growth of the remaining cells in rod morphology, cultures were plated on growth medium and quantified. Fig. 5(c) demonstrates that the number of bacteria before and after the addition of nutrients was not significantly different, suggesting that the increase in rodshaped cells was due to the transition from coccoid cells to rod-shaped cells and was not due to growth of the rodshaped cells. Since nutrient supplementation can cause reversion of cocci back to rods, these data suggest that nutrient deprivation may be the main factor in causing the transition from rod morphology to coccoid morphology under these conditions.

\section{V. cholerae in coccoid morphology can express TCP}

We next wanted to determine whether these coccoid cells were still infectious by being able to express TCP and infect the infant mouse model. While visualizing samples using FESEM, it appeared as though TCP was protruding from coccoid cells (Fig. 2). Immuno-labelling with $\alpha$-TcpA6 peptide antibodies confirmed that the structure observed 
(a)
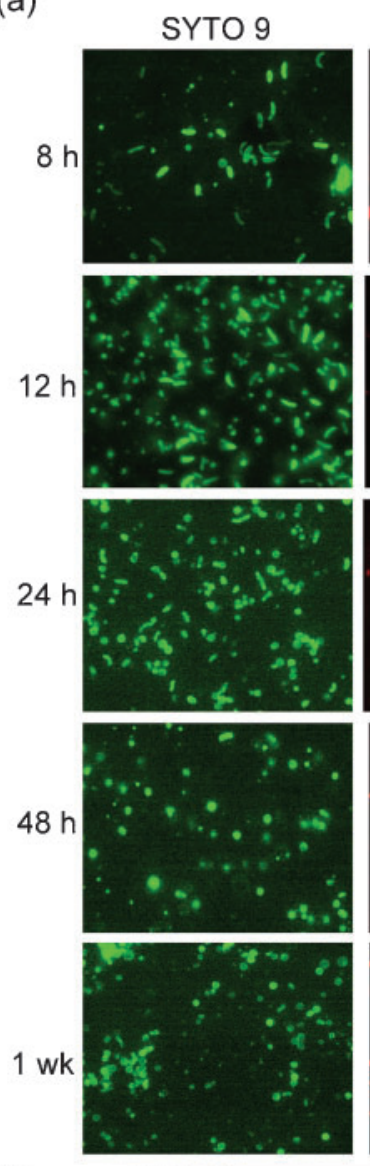

(b)

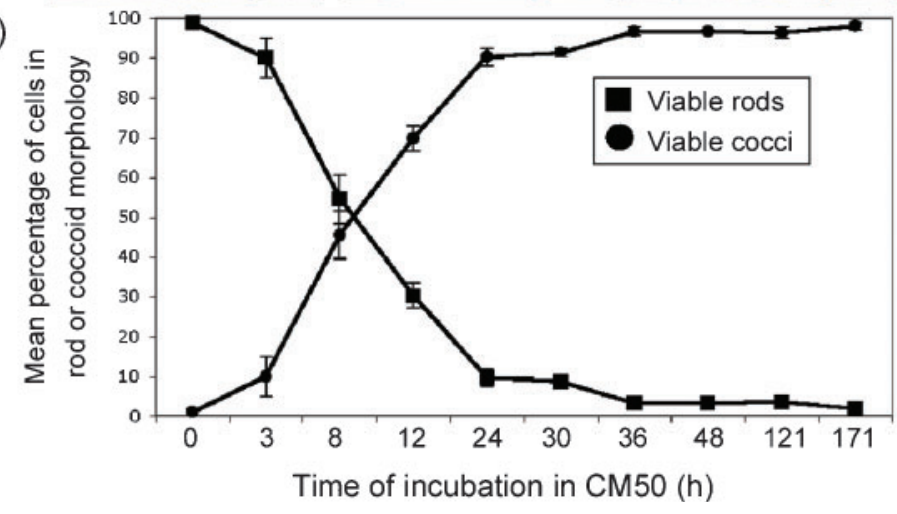

Propidium iodide
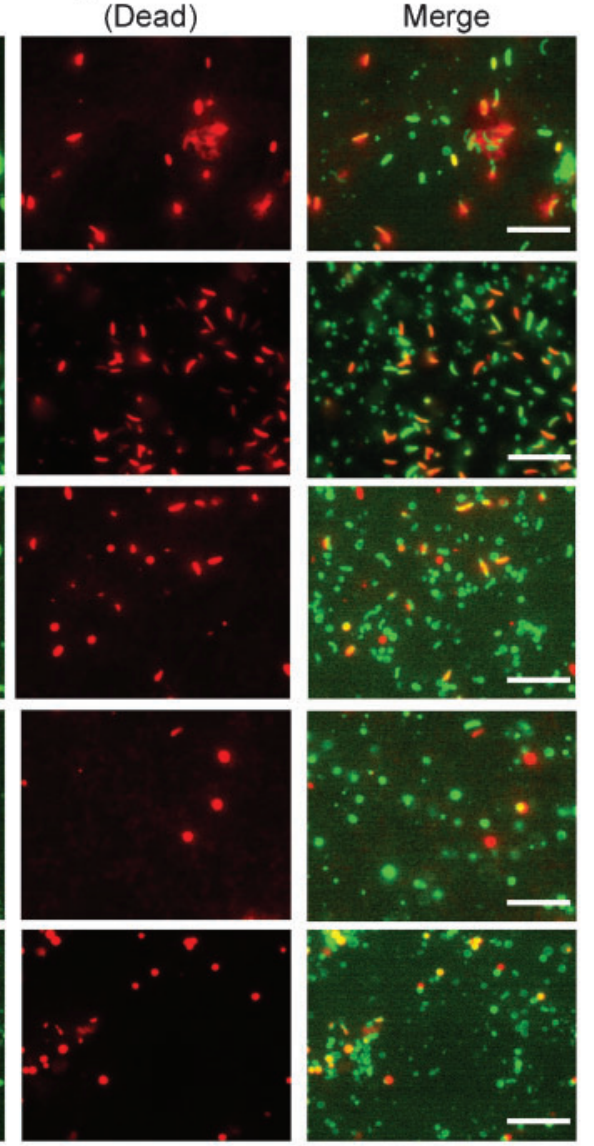

was TCP (Fig. 6a). The controls for the immuno-labelling are outlined in Fig. 1. In order to investigate whether coccoid cells can express tcpA, as opposed to the TCP filaments simply being retained from the original rodshaped cells, $\beta$-galactosidase activity was determined for each incubation time point in CM50 using a tcpA-lacZ transcriptional fusion. Since ToxT is the major activator of TCP, a $\Delta$ toxT/tcpA-lacZ strain was used as a negative control. Cells were grown for $16 \mathrm{~h}$ overnight at $37^{\circ} \mathrm{C}$ before incubation in CM50 for various time lengths. The activity determined at the $0 \mathrm{~h}$ time point indicates the point at which the cells were taken from the overnight cultures and diluted $1: 1$ prior to further incubation in
Fig. 3. Fluorescence microscopy visualizing the morphology and viability of $V$. cholerae over time. (a) BacLight was used to distinguish viable from dead $V$. cholerae in coccoid and rod morphologies after $8,12,24$ and $48 \mathrm{~h}$, and 1 week of incubation in CM50. The green fluorescence stains all cells, and the red fluorescence represents cells that are nonviable. Bars, $7.5 \mu \mathrm{m}$. (b) Graphic representation of the change in the percentage of viable cells in coccoid and rod morphology over time. Results shown are mean and SD.
CM50. As seen in Fig. 6(b), tcpA was expressed at 0 and $3 \mathrm{~h}$, when the majority of cells were in rod morphology. At $12 \mathrm{~h}$, when the majority of cells were in coccoid morphology, there was a significant increase in expression of $\operatorname{tcp} A$, and this expression was maintained up to $48 \mathrm{~h}$ of incubation (Fig. 6b). Western blotting detected TcpA at each of these time points (Fig. 6c), and the level of protein was maintained up to 1 week (data not shown). To further demonstrate that tcpA was induced when $V$. cholerae was in a coccoid morphology, we used a strain in which GFP was fused to the promoter of toxT (SJK166). ToxT is the direct activator of $t c p A$, so if ToxT is expressed, it is likely that tcpA is induced. SJK166 (promoterToxT: GFP) was grown 


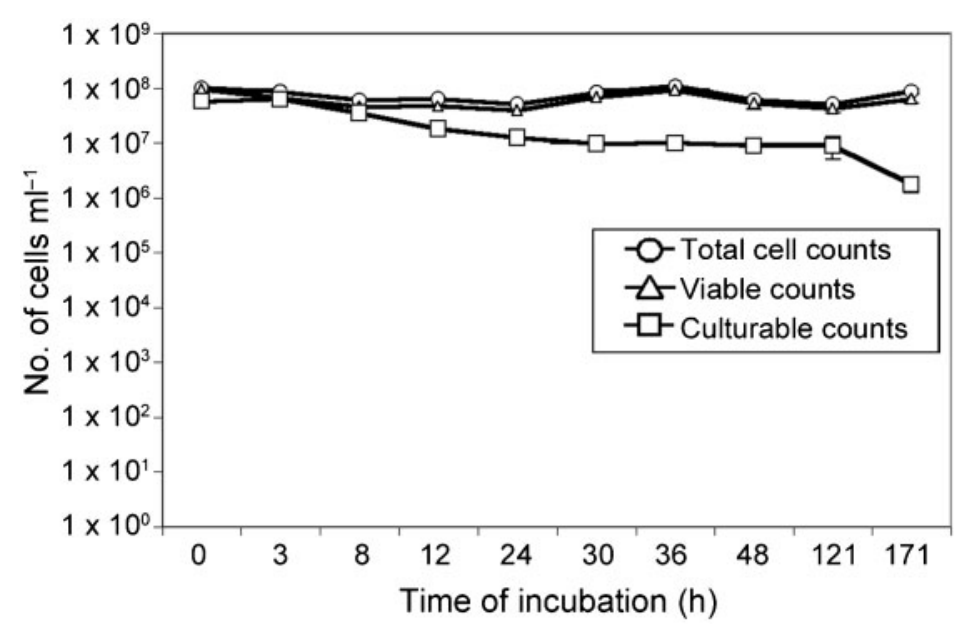

Fig. 4. Viability and culturability of $V$. cholerae. Shown are total cell counts $(\bigcirc)$, viable counts $(\triangle)$ and culturable counts $(\square)$ over time of $V$. cholerae after incubation in CM50. Results shown are mean and SD. overnight for $16 \mathrm{~h}$ at $37{ }^{\circ} \mathrm{C}$ before incubation in CM50. At $0 \mathrm{~h}$ in CM50, the $V$. cholerae cells were in rod-shaped morphology and were inducing expression of ToxT, as expected, indicated by the green fluorescence (Fig. 7a). At $48 \mathrm{~h}$, when $>90 \%$ of the cells were in coccoid morphology, a portion of these coccoid cells were expressing GFP (a)

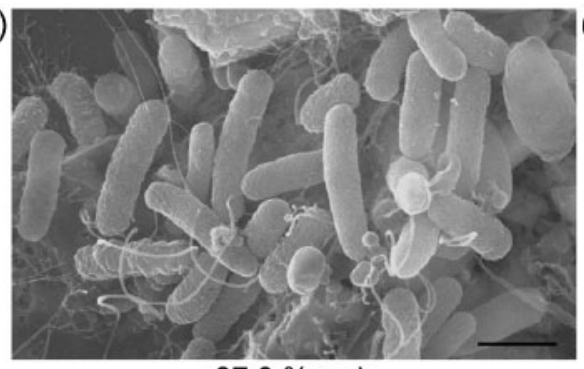

$87.9 \%$ rods

$12.1 \%$ cocci

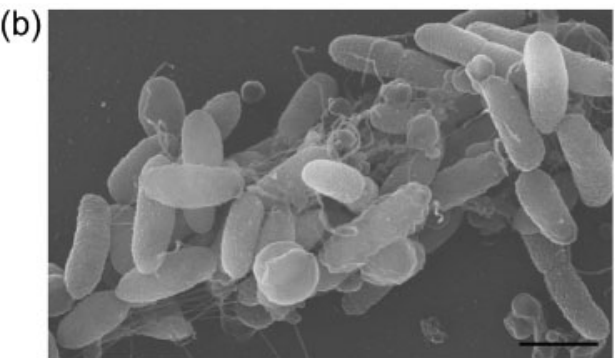

$71.9 \%$ rods

$28.1 \%$ cocci

(c)

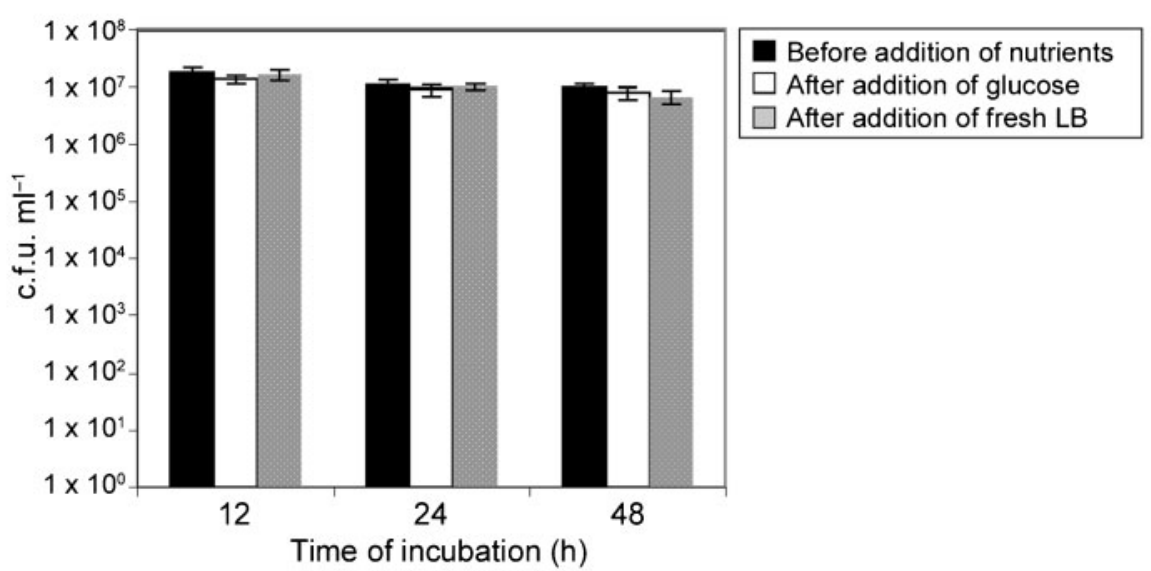

Fig. 5. $V$. cholerae cells in coccoid morphology revert back to rod-shaped morphology with nutrient supplementation. (a) Electron micrograph of $V$. cholerae cells incubated for $12 \mathrm{~h}$ in CM50, given glucose to a final concentration of $1 \%$, and incubated for an additional hour at $30^{\circ} \mathrm{C}$. (b) Electron micrograph of $V$. cholerae cells incubated for $12 \mathrm{~h}$ in $2 \mathrm{ml} \mathrm{CM} 50$, given $2 \mathrm{ml}$ fresh LB, and incubated for an additional hour at $30^{\circ} \mathrm{C}$. The number of bacteria in coccoid and rod morphology was quantified, and the percentages of these cells are given below each figure. Bars, $1 \mu \mathrm{m}$. (c) Quantification of cells grown on solid growth medium before and after the addition of nutrients. Prior to the addition of nutrients, the majority of cells were in coccoid morphology after $12 \mathrm{~h}$, as shown in Figs 2 and 3 . Results shown are mean and SD. 
(a)

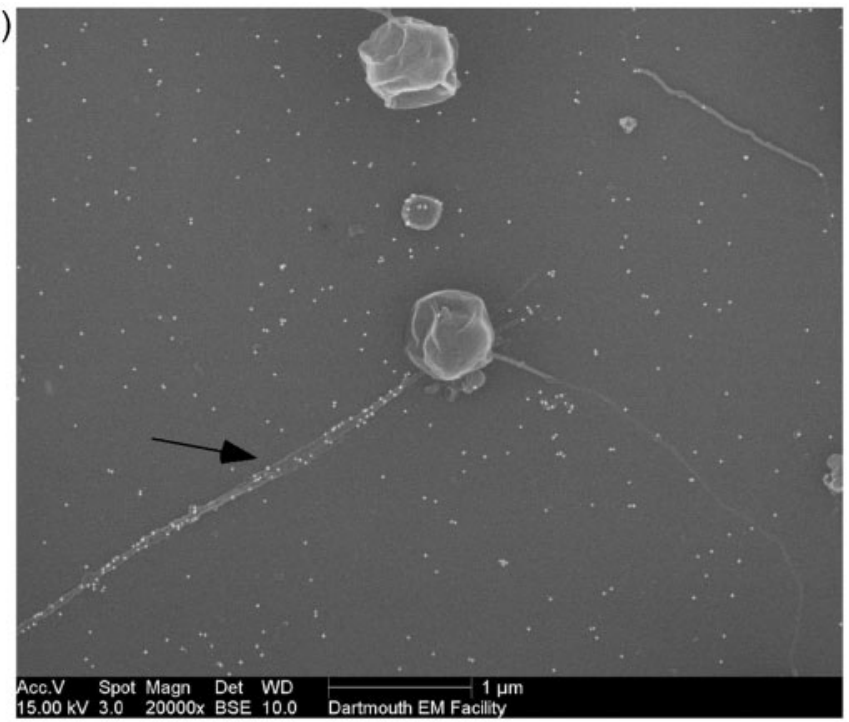

(b)

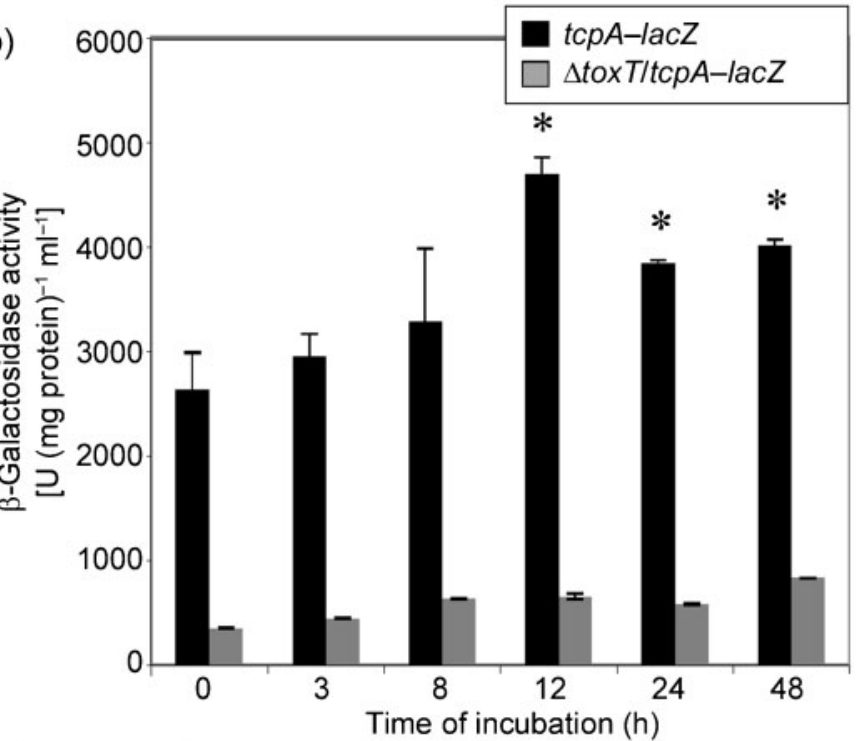

(c)

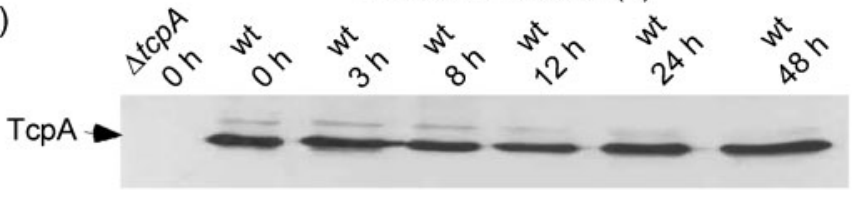

Fig. 6. Expression of tcpA by $V$. cholerae in the coccoid form. (a) Electron micrograph of coccoid $V$. cholerae incubated for $12 \mathrm{~h}$ in CM50 and then immunolabelled with $\alpha$-TcpA antibodies. The arrow indicates TCP. (b) $\beta$ Galactosidase activity of tcpA-lacZ and $\triangle$ toxTI tcpA-lacZ (negative control). Expression of tcpA was found to significantly increase compared with the $0 \mathrm{~h}$ time point, as indicated by the asterisks $(P<0.0002)$. Results shown are mean and SD. (c) Western blotting using $\alpha-$ TcpA6 peptide antibodies was performed on whole-cell samples at various time points after incubation in CM50.
(Fig. 7b), suggesting that ToxT can be expressed in coccoid cells. The negative control for this experiment used a $\Delta$ toxR/promoterToxT:GFP strain (SJK174), in which no green fluorescence was detected (Fig. 7c). Altogether, these results suggest that $t c p A$ can be expressed while $V$. cholerae is in coccoid morphology.

\section{V. cholerae cells in coccoid morphology are able to compete in colonization to the same extent as cells in rod morphology}

To determine whether cell morphology has an effect on colonization or whether there is a competitive advantage for a certain cell shape, an in vivo competitive index was performed using the infant mouse cholera model. Cells were grown under the above conditions for $3,8,12,24$ and $48 \mathrm{~h}$ in CM50. Sixteen hours prior to these time points, separate test tubes were inoculated with the reference strain $\Delta$ lac $Z$ and allowed to incubate at $30{ }^{\circ} \mathrm{C}$ for $16 \mathrm{~h}$. Without further incubation in CM50, more than $99 \%$ of the cells in this culture were rods. This culture was competed with cultures incubated in CM50 for various amounts of time (Fig. 8). The overall competitive index was calculated by taking the mean of the competitive index of five individual mice at each time point. When the reference strain was competed against the culture at the $0 \mathrm{~h}$ time point, with both cultures in rod morphology, the competitive index was approximately 1 (Fig. 8), suggesting that the two 


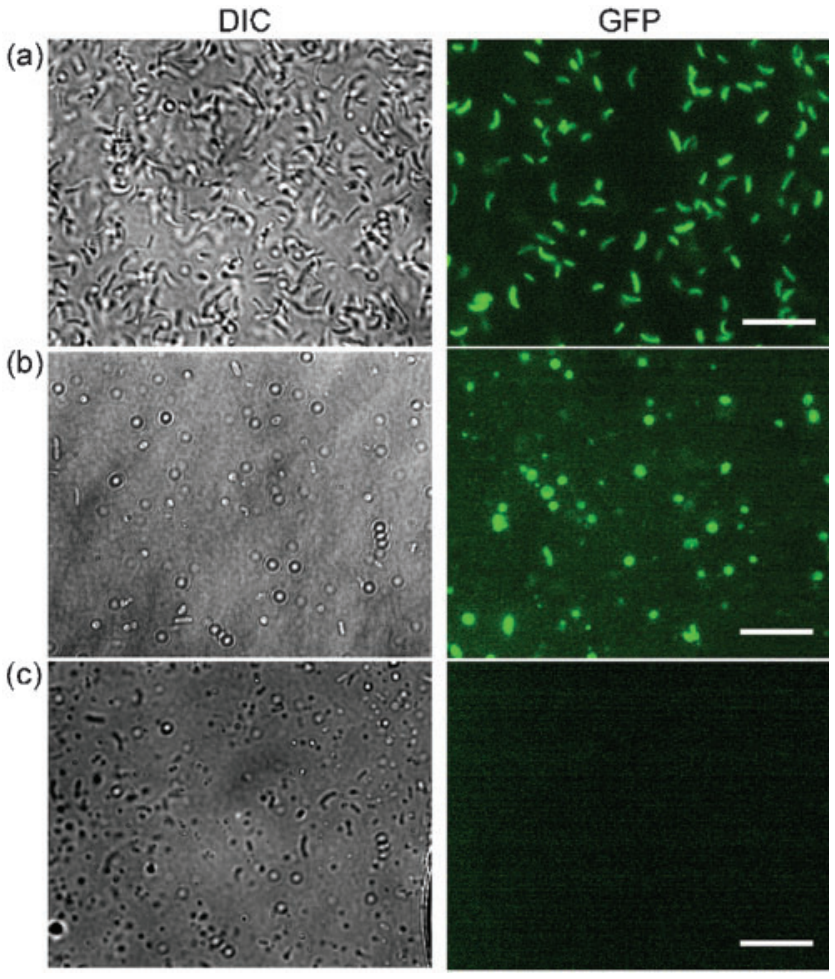

Fig. 7. Visualizing expression of ToxT using fluorescent microscopy. (a) Differential interference contrast (DIC) and GFP fluorescence images of $V$. cholerae at $0 \mathrm{~h}$ in $\mathrm{CM} 50$ with the promoter of toxT fused to GFP (promoterToxT: GFP) (SJK166, positive control). (b) DIC and GFP images of SJK166 incubated for $48 \mathrm{~h}$ in CM50. The presence of GFP indicates that ToxT is being expressed. (c) DIC and GFP images of $\Delta$ toxR/promoterToxT: GFP incubated for $48 \mathrm{~h}$ in CM50 (SJK174, negative control). Bars, $7.5 \mu \mathrm{m}$.

strains can colonize the small intestine equally, as expected. When the reference strain was competed against the test culture at the $48 \mathrm{~h}$ time point, essentially competing cells in rod morphology against cells in coccoid morphology, the competitive index was also approximately 1 (Fig. 8). Likewise, each sample at 3, 8, 12 and $24 \mathrm{~h}$ was competed against the reference strain in rod morphology, and the competitive index of these samples was also approximately 1 , suggesting that cells in coccoid morphology colonize the small intestine just as well as cells in rod morphology. While the coccoid cells are assumed to revert back to rod morphology during intestinal colonization in the presence of the nutrients in the gut, these data suggest that starting in a coccoid state is not a disadvantage for $V$. cholerae colonization of the small intestine.

\section{DISCUSSION}

Microbes need to adapt to their environment to ensure survival. $V$. cholerae not only colonizes the host intestinal environment but also persists in the aquatic environment

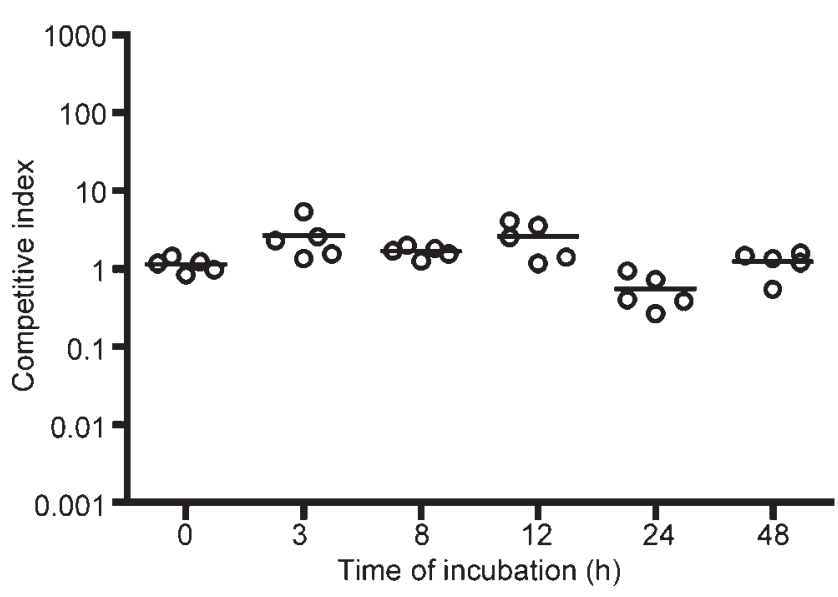

Fig. 8. Effect of coccoid morphology on colonization of the infant mouse cholera model. The reference strain was inoculated for $16 \mathrm{~h}$ prior to the CM50 incubation time points to compete bacterial cells in rod morphology against bacteria in either rod or cocci morphology (depending on the incubation time in CM50). The circles represent the competitive index of five individual mice, and the black lines represent the mean of each group.

after dissemination. During the transition between these two environments, the bacteria must develop survival strategies to adapt to their new surroundings. These mechanisms of adaptation and survival between environments are not fully understood, and current research is only beginning to shed light on this process. $V$. cholerae has been observed primarily in a rod-shaped form in the small intestine, and in a coccoid form in the VBNC state or at times of nutrient deprivation. Since coccoid and rodshaped cells have been observed in stool samples, conversion to coccoid cell morphology may represent one mechanism by which these organisms adapt during the transition from the host environment to the aquatic environment.

The aim of this study was to determine efficient conditions to study the characteristics of coccoid bacteria, independently of being in a VBNC state, as a model of the transitional state between host and aquatic environments. Here we report that $V$. cholerae rapidly changes morphology from a rod-shaped cell to a coccoid cell, beginning at $3 \mathrm{~h}$ of incubation in CM50. In earlier studies, this change to coccoid morphology, without being in a VBNC state, occurred after 15 days of incubation in nutrient-limiting media (Baker et al., 1983). When cells are incubated for five or more days at $4{ }^{\circ} \mathrm{C}$ in artificial seawater, the cells are described to enter a VBNC state (Baker et al., 1983; Carroll et al., 2001; Chaiyanan et al., 2001, 2007). We found that coccoid morphology increased with incubation time in CM50 at $30{ }^{\circ} \mathrm{C}$, with more than $90 \%$ of the total viable cells converted to coccoid morphology by $24 \mathrm{~h}$. Because these coccoid cells were still viable and culturable at least up to 1 week, this observation may suggest that a decrease 
in temperature is one condition for entry into the VBNC state. After 1 week, the culturability of these cells began to decrease, although the total viable cell count remained constant, suggesting that the cells were entering a VBNC state. Upon the addition of nutrients, these cells reverted back to rod morphology. Thus, these coccoid cells appear to be similar to the nutrient-starved cells described by Baker et al. (1983). Similar to the Baker study, we hypothesize that these cells have decreased their metabolism due to their survival in CM50. Decreasing size would enable the coccoid cell to have the greatest surface area for nutrient uptake while maintaining the least amount of cell mass (Baker et al., 1983). Although the cells may have decreased their metabolism to accommodate the lack of nutrients, they are still able to retain and express the virulence gene tcpA and can be found in aggregates mediated by TCP. Interestingly, micrographs published in a study by Chaiyanan and co-workers have also shown $V$. cholerae in coccoid morphology, with pili-like appendages resembling TCP protruding from the bacterial cells after 1 year of being in a VBNC state (Chaiyanan et al., 2007). We also found that $V$. cholerae in coccoid morphology colonizes the infant mouse to the same extent as rodshaped cells. It is highly likely that these coccoid cells revert back to rod morphology in the infant mouse; however, a study by Merrell and co-workers has suggested that the small intestine of the suckling mouse is nutrient-limited, since $V$. cholerae must actively employ multiple pathways for energy source acquisition and survival (Merrell et al., 2002). Therefore, it is conceivable that a population of cells in the intestine could be in the coccoid form in response to nutrient limitation. Our data suggest that cells in coccoid morphology are not at a disadvantage in virulence based upon their cell shape.

Similarly, it has been shown that CVEC are fully virulent in rabbit intestines, and a heterogeneous mixture of biofilmlike aggregates and free-swimming planktonic cells of $V$. cholerae is found in the stools of cholera patients (Faruque et al., 2006). We do not suggest that the coccoid cells described in this manuscript represent the biology of all described coccoid cells of $V$. cholerae, such as CVEC or VBNC cells. Different experimental conditions can yield different phenotypic characteristics. We demonstrate under our described conditions that these coccoid cells are viable, culturable on conventional growth media, express TCP, and are as pathogenic as rod-shaped cells. It has been described that when $V$. cholerae enters a VBNC state, the bacteria are not culturable on conventional growth media, although the cells remain viable and display active metabolism (Rahman et al., 1994) and transcription (Lleò et al., 2000), and can divide again upon restoration of favourable environmental conditions (i.e. nutrient supplementation, increased temperature, host environment) (Kamruzzaman et al., 2010; Nilsson et al., 1991; Smith \& Oliver, 2006a).

The expression of $t c p$ while in coccoid morphology may aid in transmission and survival of $V$. cholerae in the environment. There is some evidence to suggest that the factors important for the survival of bacteria in the environment may also be the same virulence factors that cause disease. GbpA, a characterized GlcNAc-binding protein, is an example of a $V$. cholerae colonization factor utilized in both the host and the aquatic environment (Kirn et al., 2005). In addition, pathogenic strains of a variety of bacterial species have been characterized to retain and express virulence factors when in the VBNC state (Du et al., 2007; Fischer-Le Saux et al., 2002; Rahman et al., 1996; Smith \& Oliver, 2006b), and also maintain antibiotic resistance (Kamruzzaman et al., 2010; Lleò et al., 2003). In the host environment, virulence factors such as TCP are required for colonization and persistence in the small intestine. Without TCP, the bacteria are cleared from the host rapidly (Kirn \& Taylor, 2005; Kirn et al., 2000). In the environment, bacterial cells interact with chitinaceous surfaces to generate biofilms that may promote their survival and persistence (Watnick \& Kolter, 1999). A study by Reguera and Kolter found that TCP is required for biofilm differentiation on chitinaceous surfaces by mediating bacterial interactions. Biofilms composed of cells lacking TCP have reduced ecological fitness (Reguera \& Kolter, 2005), suggesting that TCP expression in the environment may be one survival mechanism of $V$. cholerae under these conditions. Therefore, TCP may be one factor that $V$. cholerae utilizes for survival and persistence in both the host and the aquatic environment.

The mechanisms by which coccoid cells are produced remain largely unknown, but their very existence has important implications for microbial ecology and for the control of infectious disease. The recent studies of aggregates of coccoid and rod-shaped $V$. cholerae cells in the water-diluted stools of cholera patients (CVEC) (Faruque et al., 2006; Kamruzzaman et al., 2010) suggest that conversion to a coccoid form may happen during the later stages of infection or during dissemination. Since TCP is required for microcolony/aggregate formation, and aggregates have been found in the stools of cholera patients (Kamruzzaman et al., 2010), it is highly likely that TCP is mediating the bacterial interactions within these aggregates. These aggregates are able to colonize 10-100-fold better than the reference strain in the infant mouse cholera model (Faruque et al., 2006), suggesting that $V$. cholerae in coccoid morphology may play a role in pathogenicity and transmission.

Although there have been many studies describing $V$. cholerae in the intestinal environment and the VBNC state, there have been few studies describing the mechanisms of survival that bacteria utilize during the transition between these two environments. The steps from infection in the human host to persistence in the VBNC state have not been fully investigated, and altering morphology into a coccoid cell may be one step in this transition. Coccoid cell morphology may represent a survival strategy that helps these organisms to persist during nutrient-limited conditions, and expressing virulence factors such as TCP may 
enhance the protection of the bacteria by mediating the formation of microcolonies or aggregates in the aquatic environment. Understanding the factors involved in survival of $V$. cholerae could provide new insights into novel methods of preventing transmission.

\section{ACKNOWLEDGEMENTS}

We are grateful to Louisa Howard and the Ripple Imaging Facility at Dartmouth for the production of the FESEM images. This work was supported by National Institutes of Health (NIH) grant AI25096 to R.K.T. S.J.K. was also supported by the NIH training grant T32GM08704.

\section{REFERENCES}

Baker, R. M., Singleton, F. L. \& Hood, M. A. (1983). Effects of nutrient deprivation on Vibrio cholerae. Appl Environ Microbiol 46, 930-940.

Bina, J., Zhu, J., Dziejman, M., Faruque, S., Calderwood, S. \& Mekalanos, J. (2003). ToxR regulon of Vibrio cholerae and its expression in vibrios shed by cholera patients. Proc Natl Acad Sci U S A 100, 2801-2806.

Boulos, L., Prévost, M., Barbeau, B., Coallier, J. \& Desjardins, R. (1999). LIVE/DEAD BacLight: application of a new rapid staining method for direct enumeration of viable and total bacteria in drinking water. J Microbiol Methods 37, 77-86.

Carroll, J. W., Mateescu, M. C., Chava, K., Colwell, R. R. \& Bej, A. K. (2001). Response and tolerance of toxigenic Vibro cholerae O1 to cold temperatures. Antonie van Leeuwenhoek 79, 377-384.

Chaiyanan, S., Chaiyanan, S., Huq, A., Maugel, T. \& Colwell, R. R. (2001). Viability of the nonculturable Vibrio cholerae O1 and O139. Syst Appl Microbiol 24, 331-341.

Chaiyanan, S., Chaiyanan, S., Grim, C., Maugel, T., Huq, A. \& Colwell, R. R. (2007). Ultrastructure of coccoid viable but non-culturable Vibrio cholerae. Environ Microbiol 9, 393-402.

Colwell, R. R. (2000). Viable but nonculturable bacteria: a survival strategy. J Infect Chemother 6, 121-125.

Cooper, S. (1997). Division pattern of a round mutant of Escherichia coli. J Bacteriol 179, 5582-5584.

Corbin, B. D., Yu, X. C. \& Margolin, W. (2002). Exploring intracellular space: function of the Min system in round-shaped Escherichia coli. EMBO J 21, 1998-2008.

Du, M., Chen, J., Zhang, X., Li, A., Li, Y. \& Wang, Y. (2007). Retention of virulence in a viable but nonculturable Edwardsiella tarda isolate. Appl Environ Microbiol 73, 1349-1354.

Faruque, S. M., Biswas, K., Udden, S. M., Ahmad, Q. S., Sack, D. A., Nair, G. B. \& Mekalanos, J. J. (2006). Transmissibility of cholera: in vivo-formed biofilms and their relationship to infectivity and persistence in the environment. Proc Natl Acad Sci U S A 103, 6350-6355.

Felter, R. A., Colwell, R. R. \& Chapman, G. B. (1969). Morphology and round body formation in Vibrio marinus. J Bacteriol 99, 326-335.

Fischer-Le Saux, M., Hervio-Heath, D., Loaec, S., Colwell, R. R. \& Pommepuy, M. (2002). Detection of cytotoxin-hemolysin mRNA in nonculturable populations of environmental and clinical Vibrio vulnificus strains in artificial seawater. Appl Environ Microbiol 68, 5641-5646.

Halpern, M., Broza, Y. B., Mittler, S., Arakawa, E. \& Broza, M. (2004). Chironomid egg masses as a natural reservoir of Vibrio cholerae nonO1 and non-O139 in freshwater habitats. Microb Ecol 47, 341-349.
Henrici, A. T. (1925). A statistical study of the form and growth of the cholera vibrio: three plates. J Infect Dis 37, 75-81.

Herrington, D. A., Hall, R. H., Losonsky, G., Mekalanos, J. J., Taylor, R. K. \& Levine, M. M. (1988). Toxin, toxin-coregulated pili, and the toxR regulon are essential for Vibrio cholerae pathogenesis in humans. J Exp Med 168, 1487-1492.

Hulbert, R. R. \& Taylor, R. K. (2002). Mechanism of ToxT-dependent transcriptional activation at the Vibrio cholerae tcpA promoter. J Bacteriol 184, 5533-5544.

Huq, A., Colwell, R. R., Rahman, R., Ali, A., Chowdhury, M. A., Parveen, S., Sack, D. A. \& Russek-Cohen, E. (1990). Detection of Vibrio cholerae $\mathrm{O} 1$ in the aquatic environment by fluorescentmonoclonal antibody and culture methods. Appl Environ Microbiol 56, 2370-2373.

Islam, M. S., Drasar, B. S. \& Bradley, D. J. (1989). Attachment of toxigenic Vibrio cholerae $\mathrm{O} 1$ to various freshwater plants and survival with a filamentous green alga, Rhizoclonium fontanum. J Trop Med Hyg 92, 396-401.

Johnston, M. D. \& Brown, M. H. (2002). An investigation into the changed physiological state of Vibrio bacteria as a survival mechanism in response to cold temperatures and studies on their sensitivity to heating and freezing. J Appl Microbiol 92, 1066-1077.

Justice, S. S., Hung, C., Theriot, J. A., Fletcher, D. A., Anderson, G. G., Footer, M. J. \& Hultgren, S. J. (2004). Differentiation and developmental pathways of uropathogenic Escherichia coli in urinary tract pathogenesis. Proc Natl Acad Sci U S A 101, 1333-1338.

Kamruzzaman, M., Udden, S. M., Cameron, D. E., Calderwood, S. B., Nair, G. B., Mekalanos, J. J. \& Faruque, S. M. (2010). Quorumregulated biofilms enhance the development of conditionally viable, environmental Vibrio cholerae. Proc Natl Acad Sci U S A 107, 15881593.

Kaper, J. B., Morris, J. G., Jr \& Levine, M. M. (1995). Cholera. Clin Microbiol Rev 8, 48-86.

Karaolis, D. K., Somara, S., Maneval, D. R., Jr, Johnson, J. A. \& Kaper, J. B. (1999). A bacteriophage encoding a pathogenicity island, a typeIV pilus and a phage receptor in cholera bacteria. Nature 399, 375379.

Kirn, T. J. \& Taylor, R. K. (2005). TcpF is a soluble colonization factor and protective antigen secreted by El Tor and classical O1 and O139 Vibrio cholerae serogroups. Infect Immun 73, 4461-4470.

Kirn, T. J., Lafferty, M. J., Sandoe, C. M. \& Taylor, R. K. (2000). Delineation of pilin domains required for bacterial association into microcolonies and intestinal colonization by Vibrio cholerae. Mol Microbiol 35, 896-910.

Kirn, T. J., Jude, B. A. \& Taylor, R. K. (2005). A colonization factor links Vibrio cholerae environmental survival and human infection. Nature 438, 863-866.

Koch, R. (1884). Über die Cholerabakterien. Dtsch Med Wochenschr 10, 725-728.

Krogfelt, K. A., Poulsen, L. K. \& Molin, S. (1993). Identification of coccoid Escherichia coli BJ4 cells in the large intestine of streptomycin-treated mice. Infect Immun 61, 5029-5034.

Lleò, M. M., Pierobon, S., Tafi, M. C., Signoretto, C. \& Canepari, P. (2000). mRNA detection by reverse transcription-PCR for monitoring viability over time in an Enterococcus faecalis viable but nonculturable population maintained in a laboratory microcosm. Appl Environ Microbiol 66, 4564-4567.

Lleò, M. M., Bonato, B., Signoretto, C. \& Canepari, P. (2003). Vancomycin resistance is maintained in enterococci in the viable but nonculturable state and after division is resumed. Antimicrob Agents Chemother 47, 1154-1156. 
Merrell, D. S., Hava, D. L. \& Camilli, A. (2002). Identification of novel factors involved in colonization and acid tolerance of Vibrio cholerae. Mol Microbiol 43, 1471-1491.

Miller, J. H. (1972). Experiments in Molecular Genetics. Cold Spring Harbor, NY: Cold Spring Harbor Laboratory.

Nilsson, L., Oliver, J. D. \& Kjelleberg, S. (1991). Resuscitation of Vibrio vulnificus from the viable but nonculturable state. J Bacteriol 173, 5054-5059.

Nye, M. B., Pfau, J. D., Skorupski, K. \& Taylor, R. K. (2000). Vibrio cholerae $\mathrm{H}-\mathrm{NS}$ silences virulence gene expression at multiple steps in the ToxR regulatory cascade. J Bacteriol 182, 4295-4303.

Oliver, J. D. (2005). The viable but nonculturable state in bacteria. J Microbiol 43 (Spec No), 93-100.

Oliver, J. D., Nilsson, L. \& Kjelleberg, S. (1991). Formation of nonculturable Vibrio vulnificus cells and its relationship to the starvation state. Appl Environ Microbiol 57, 2640-2644.

Rahman, I., Shahamat, M., Kirchman, P. A., Russek-Cohen, E. \& Colwell, R. R. (1994). Methionine uptake and cytopathogenicity of viable but nonculturable Shigella dysenteriae type 1. Appl Environ Microbiol 60, 3573-3578.

Rahman, I., Shahamat, M., Chowdhury, M. A. \& Colwell, R. R. (1996). Potential virulence of viable but nonculturable Shigella dysenteriae type 1. Appl Environ Microbiol 62, 115-120.

Reguera, G. \& Kolter, R. (2005). Virulence and the environment: a novel role for Vibrio cholerae toxin-coregulated pili in biofilm formation on chitin. J Bacteriol 187, 3551-3555.

Rice, S. A., McDougald, D. \& Kjelleberg, S. (2000). Vibrio vulnificus: a physiological and genetic approach to the viable but nonculturable response. J Infect Chemother 6, 115-120.
Signoretto, C., Di Stefano, F. \& Canepari, P. (1996). Modified peptidoglycan chemical composition in shape-altered Escherichia coli. Microbiology 142, 1919-1926.

Smith, B. \& Oliver, J. D. (2006a). In situ gene expression by Vibrio vulnificus. Appl Environ Microbiol 72, 2244-2246.

Smith, B. \& Oliver, J. D. (2006b). In situ and in vitro gene expression by Vibrio vulnificus during entry into, persistence within, and resuscitation from the viable but nonculturable state. Appl Environ Microbiol 72, 1445-1451.

Sun, D. X., Seyer, J. M., Kovari, I., Sumrada, R. A. \& Taylor, R. K. (1991). Localization of protective epitopes within the pilin subunit of the Vibrio cholerae toxin-coregulated pilus. Infect Immun 59, 114-118.

Tamplin, M. L., Gauzens, A. L., Huq, A., Sack, D. A. \& Colwell, R. R. (1990). Attachment of Vibrio cholerae serogroup O1 to zooplankton and phytoplankton of Bangladesh waters. Appl Environ Microbiol 56, 1977-1980.

Taylor, R. K., Miller, V. L., Furlong, D. B. \& Mekalanos, J. J. (1986). Identification of a pilus colonization factor that is coordinately regulated with cholera toxin. Ann Sclavo Collana Monogr 3, 51-61.

Taylor, R. K., Miller, V. L., Furlong, D. B. \& Mekalanos, J. J. (1987). Use of phoA gene fusions to identify a pilus colonization factor coordinately regulated with cholera toxin. Proc Natl Acad Sci U S A 84, 2833-2837.

Watnick, P. I. \& Kolter, R. (1999). Steps in the development of a Vibrio cholerae El Tor biofilm. Mol Microbiol 34, 586-595.

Weichart, D. \& Kjelleberg, S. (1996). Stress resistance and recovery potential of culturable and viable but nonculturable cells of Vibrio vulnificus. Microbiology 142, 845-853.

Edited by: P. van der Ley 